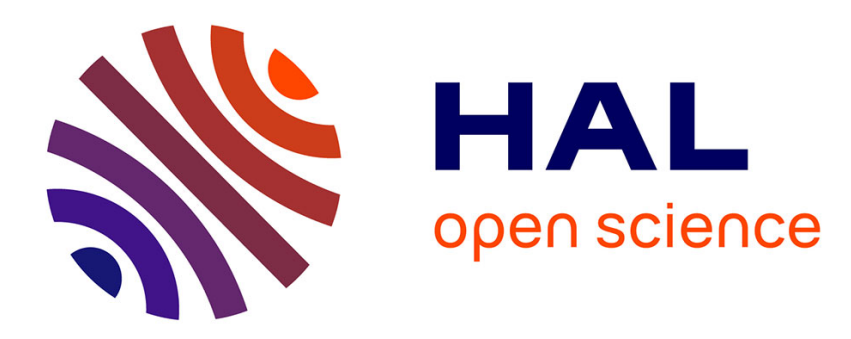

\title{
Ultra low frequency pressure transducer calibration
}

A. Semenov

\section{To cite this version:}

A. Semenov. Ultra low frequency pressure transducer calibration. Journal de Physique IV Proceedings, 1994, 04 (C5), pp.C7-251-C7-254. 10.1051/.jp4:1994550 . jpa-00253045

\section{HAL Id: jpa-00253045 https://hal.science/jpa-00253045}

Submitted on 1 Jan 1994

HAL is a multi-disciplinary open access archive for the deposit and dissemination of scientific research documents, whether they are published or not. The documents may come from teaching and research institutions in France or abroad, or from public or private research centers.
L'archive ouverte pluridisciplinaire HAL, est destinée au dépôt et à la diffusion de documents scientifiques de niveau recherche, publiés ou non, émanant des établissements d'enseignement et de recherche français ou étrangers, des laboratoires publics ou privés. 


\title{
Ultra low frequency pressure transducer calibration
}

\author{
A.G. SEMENOV
}

N.N. Andreev Acoustics Institute, Russian Academy of Sciences, 4 Shvernik str, Moscow 117036, Russia

\begin{abstract}
This work is devoted to description of practical experience in solution of several scientific and technical problems arising in ocean environmental ultra low frequency acoustic field measurements fulfilled by means of pressure piezoelectric transducer. Ultra low frequency (ULF) range presented here lies in natural nonstationary noise field periods interval from 1000 to 10 seconds. In the course of development of measuring utility solution of following practical problems was proposed: - construction special very high capacity up to several $\mathrm{mF}$ piezoelectric pressure probe and special mechanical grid protecting the probe from environmental currents; constructing and adjusting of first stage special type charge preamplifier adequately working in ULF range with input impedance up to $10^{13} \mathrm{~W}$ and maximum input charge $10^{5} \mathrm{pC}$; - construction of special mechanical and temperature calibration means providing very slow harmonic change of static pressure with amplitude accuracy from several millimeters of water gauge and temperature accuracy from $0.1^{\circ} \mathrm{C}$ on the surface of transducer.
\end{abstract}

\section{INTRODUCTION}

Classical example of multipoint measurement of ULF pressure field was described in early work[ ] published in the end of 50's where special reliable string vibration frequency dependence on tension based transducers ("Vibratron") were used for field measurement. Experimental data obtained in several Pacific Ocean regions were obtained and widely used for estimation of pressure fields in practice: Nevertheless, problems of proper calibration and temperature sensitivity still exist there. Piezoelectric transducers are much more widely spread in ocean experiment. That is why it is important to develop means for measurement ULF pressure fields by such transducers. A row of technical problems are likely to be encountered when ULF measurements of nonstationary ocean noise fields in the periods interval from 1000 to 10 seconds are attempted by means of piezoelectric pressure transducers. They are known to be related to the transducer, preamplifier as, well as calibration means constructions.

\section{TRANSDUCERS AND PREAMPLIFIERS}

To measure natural ULF pressure variations in the ocean two possible types of transducers were tested - specially constructed, with extremely high capacitance to be used with conventional preamplifiers and conventionally used resembling Bruel Kjaer 8100 or 8104 type hydrophones [2] to be used with charge 
preamplifiers resembling 2651 type B \& K. Construction of newly proposed transducers was presented before [2].

The construction of conventional transducers, as it was mentioned, resembles B \& $\mathrm{K} 8100$ or 8104 hydrophones, but their capacitance was made a little higher [2]. Special mechanical grids protecting the probe from environmental currents, for both types of transducers used in experiment were developed. Inspite of the fact that conventional preamplifiers specially designed for extremely high capacitance transducers were successfully tested in ocean experiment [2], it is still important to notice ,that after thorough analysis we come to conclusion that equality of serial conventional preamplifiers properties attainable in multipoint ocean experiment are more important. Nevertheless, all problems of newly designed preamplifier calibration and temperature sensitivity which will be analyzed below are actual as well as for conventional preamplifiers, while problems of artificial drifts are of less importance [2].

\section{CALIBRATION}

To provide measuring utility calibration following program was proposed - calibration by sinusoidal pressure signal in periods band from 1000 to $10 \mathrm{sec}$, temperature and temperature gradient influence investigation. All calibration results described below are obtained by means of model ethalone measuring utility consisting of factory passportized B \& K hydrophone 8100 or 8104 types and charge amplifier 2651 type to avoid additional systematic errors which could be encountered if specially constructed conventional hydrophone and amplifier directly used in ocean experiment would be tested, as well as to demonstrate calibration means possibility. Calibration utility shown on Fig. 1 realizes one of absolute transducer calibration methods -hydrostatic method. It is based on periodical change of static pressure acting on hydrophone surface. It is known as well as "vibrating column" method, for pressure is changed by means of fluid column or transducer immersion depth change. These two possibilities in test vessel could be realized by vertical vibrations of immersed hydrophone, by vibrations of specially introduced immersed body with hydrophone at rest or by vibrations of special adjacent vessel communicated with test vessel. All these possibilities were used in practice and two last are preferable due to substantial insulation of artificial currents streamlining immersed hydrophone attained. Cylindrical vessels and immersed body shapes are more convenient. Value of periodical pressure for test facility could be expressed in the form:

$$
P=\rho \cdot g(H+a D h \sin \omega t)=p_{s}+p_{a}(t)
$$

where $p_{s}$ and $p_{a}$ - are static and alternative components of hydrostatic pressure correspondingly, Dh vibrating body periodic displacement amplitude, $\mathrm{H}$ - depth of hydrophone immersion, $\mathrm{w}$ - electromotor angular velocity, $\rho$ and $\mathrm{g}$ - fluid density and local gravity acceleration constant, a - dimensionless constant depending on test facility construction, for instance, if test vessel crossection equals to $S$ and specially introduced immersed body crossection $-s$, then a equals to $s / S$. Sensitivity $M$ of measuring utility calibrated could be calculated by means of direct measurement of output voltage $U$ and alternative pressure $p$ amplitudes for frequency $w$ according to expression - $M=U / p$. Calibration curve of model utility with 8104 type hydrophone in periods range between 1000 and $10 \mathrm{sec}$ is shown in Table 1. Data are based on several different arbitrary taken realizations, resembling results were obtained for 8100 type B \& K hydrophone. 


\begin{tabular}{|l|llll|}
\hline & \multicolumn{5}{|l|}{$\begin{array}{l}\text { Period } \\
\text { duration } \\
M_{p}, \mathrm{mv} / \mathrm{Pa}\end{array}$} & 1000 & 250 & sec & 10 \\
\hline$M_{p}$, mean & 62.0 & 36.1 & 33.4 & 32.0 \\
$M_{p}, \min$ & 14.8 & 32.5 & 32.7 & 31.9 \\
$M_{p}, \max$ & 176.0 & 40.3 & 43.3 & 32.5 \\
\hline
\end{tabular}

Table 1

It is evident that calibration data dispersion is increasing with increasing signal period duration and attains $+15 \mathrm{~dB}$ for $1000 \mathrm{sec}$ duration. This dispersion is not shown in conventional factory passport for hydrophones are calibrated on factory in the periods range not longer than $10 \mathrm{sec}$. Our analysis shows that this dispersion is related directly to measuring utility temperature sensitivity. For instance, in factory passport of 8100 type hydrophone temperature transient sensitivity measured with B \& K type preamplifier 2626 is shown to be $70 \mathrm{~Pa} / \mathrm{C}$ for longest period $3 \mathrm{sec}$ of measuring frequency band. Examples of temperature sensitivity were presented in paper [2], where voltage impulses corresponding to temperature drops during hydrophone immersion (positive) and take-off (negative) from calibration vessels are observed. Temperature difference of water and environment air was of an order of several grades. To make quantitative estimates of measuring utility temperature impulse sensitivity, special electric heat source and precise temperature measuring device were used in calibration vessel. Temperature and temperature gradient were measured simultaneously by means of digital voltmeter connected to temperature resistance, with accuracy not worse than $0.1 \mathrm{C}$ for temperature, corresponding to temperature sensitivity accuracy approximately $10 \%$. Mean value of temperature sensitivity was measured in our experiments to be $3.4 \mathrm{~V} / \mathrm{C}$. This value could be expressed in pressure units by means of data revealed in Table 1. For instance, for longest period $300 \mathrm{sec}$ of measuring frequency band, taking pressure sensitivity to be equal to $50 \mathrm{mV} / \mathrm{Pa}$ passportized for B \& K hydrophone 8100 type, temperature sensitivity was shown to be $6.810 \mathrm{~Pa} / \mathrm{C}$, while for longest period $30 \mathrm{sec}$ of measuring frequency band, taking passport sensitivity to be equal to $500 \mathrm{mV} / \mathrm{Pa}$, temperature sensitivity is measured to be (1.1-1.4) 10 $\mathrm{Pa} / \mathrm{C}$ with mentioned above accuracy. One can easily understand, that comparably small temperature drop $-0.1 \mathrm{C}$, frequently met in ocean conditions, is equivalent in ULF pressure measurements to pressure drop 6-7.510 Pa - quite rarely observed in ocean. Influence of temperature gradients on measured ULF pressure value were also estimated during calibration. Two types of temperature change processes were analyzed - slow, with temperature gradients of an order of $(2-4) 10 \mathrm{C} / \mathrm{sec}$, and fast - with temperature gradients approximately $10 \mathrm{C} / \mathrm{sec}$. Expected relative accuracy of measurement in this case is $20 \%$. Mean value of temperature gradient sensitivity is shown to be $2.110 \mathrm{~V} / \mathrm{C} / \mathrm{sec}$ - for slow and $1.610 \mathrm{~V} /$ $\mathrm{C} / \mathrm{sec}$ - for fast temperature changes. Anyway, calibration measurements fulfilled give foundation to believe, that in measuring utility tested voltage proportional to temperature gradient is produced with mean sensitivity to temperature gradient $(1-2) 10 \mathrm{~V} / \mathrm{C} / \mathrm{sec}$. This value is very important practically, for, if value of ULF voltage to be measured on the output is limited, as it is, for instance, for $2651 \mathrm{~B} \& \mathrm{~K}$ preamplifier, by $+5 \mathrm{~V}$, then measuring utility could successfully operate in very narrow range of temperature gradients, not higher, than, for our case, (2-5) $10 \mathrm{C} / \mathrm{sec}$. Such gradients are quite frequently met in ocean. Thus, it is shown by direct calibration, that measuring utility tested in conditions close to naturally existing in ocean experiment, could produce artificial signals explained by its temperature and temperature gradient sensitivity, not related directly with ULF pressure fields to be measured. This 
temperature sensitivity should be at least taken into account, when experimental results are analyzed, and probably could be corrected by special technical measures.

\section{REFERENCES}

[1] Munk W H, Snodgrass F E and Tucker M J, Spectra of low frequency ocean waves, , Bulletin of the Scripps institution of the Oceanography of the University of California, 7, 4(1959) 283-362.

[2] Gromov Yu and Semenov A,Ultra-low frequency prssure transducers calibration and development, Underwater Defence Technologies'93 Conference, Cannes ,France , June 1993

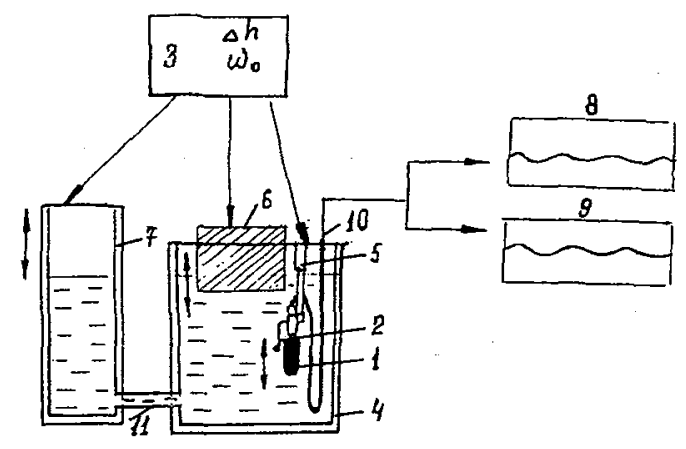

Fig. L. Calibration utility scheme. 1-tested transducer, 2-temperature sensor, 3-precision driving block, controlling amplitude and frequency of vertical vibrations; 4-test vessel, 5-transducer holder, 6-immersed body, 7-adjacent communicated vessel, 8,9-pressure and temperature registrators, 10-cable, 11-communication tube 